Akreditasi Ristekdikti,

No: 30/E/KPT/2019 (Sinta 4)

Paradigma,

DOI: https://doi.org/10.31294/p.v23i2.11419

Vol. 23, No. 2, September 2021

P-ISSN 1410-5063, E-ISSN: 2579-3500

\title{
Tata Kelola Sistem Informasi PT. Maspion Menggunakan Framework Cobit 4.1 Domain Acquire And Implement
}

\author{
Andi Saryoko $^{1^{*}}$, Agus Junaidi ${ }^{2}$, Sopiyan Dalis ${ }^{3}$, Fitrayuda Rivaldy ${ }^{4}$ \\ 1,4 Universitas Nusa Mandiri \\ e-mail: andi.asy@nusamandiri.ac.id, fitrayuda0602@nusamandiri.ac.id \\ ${ }^{2,3}$ Universitas Bina Sarana Informatika \\ e-mail: agus.asj@bsi.ac.id, sopiyan.spd@bsi.ac.id
}

\begin{abstract}
Abstrak - Perkembangan teknologi informasi mengalami kemajuan yang begitu pesat pada saat ini . Kemajuan TI ini menjadikan setiap penggunanya dapat mengakses berbagai data-data dan informasi-informasi yang dibutuhkan dengan mudah dan cepat. Peningkatan peran TI dalam perusahaan yang terjadi saat ini sebenarnya juga diikuti dengan perubahan proses bisnis perusahaan. Pengembangan strategi bisnis selalu dikaitkan dengan pengembangan strategi TI. Salah satu tata kelola IT yang dapat diimplementasikan dalam perusahaan yaitu dengan melakukan evaluasi teknologi informasi atau sistem informasi. Prinsip-prinsip tata kelola teknologi informasi harus dilakukan secara terintegrasi, sebagaimana fungsi-fungsi manajemen dilaksanakan pada sebuah organisasi publik. Salah satu metode pengelolaan teknologi informasi yang digunakan secara luas adalah IT governance yang terdapat pada COBIT (Control Objectives for Information and Related Technology). Oleh karena itu, penulis ingin melakukan audit terhadap tata kelola teknologi informasi yang sudah berjalan di PT. Maspion. Evaluasi (Audit) bertujuan untuk menilai, memonitor, dan memastikan bahwa sistem informasi perusahaan dapat mengelola integritas data dengan baik dan mampu beroperasi secara efektif sesuai dengan tujuan perusahaan dan tujuan IT perusahaan.
\end{abstract}

Kata Kunci: Tata Kelola, Sistem Informasi, Framework COBIT

\begin{abstract}
The development of information technology has progressed so rapidly at this time. This IT allows every user to easily and quickly access the progress of various data and information needed. The increasing role of IT in the company that is happening today is actually also followed by changes in the company's business processes. Business strategy development is always with IT strategy development. One of the IT governance that can be implemented in the company is by evaluating information technology or information systems. The principles of information technology governance must be carried out in an integrated manner, as management functions are carried out in a public organization. One of the widely used information technology management methods is IT governance in COBIT (Control Objectives for Information and Related Technology). Therefore, the authors want to conduct an audit of the governance of information technology that has been running at PT. Maspion. Evaluation (Audit) aims to assess, monitor, and ensure that the company's information system can manage data integrity properly and is able to operate effectively in accordance with company goals and company IT goals.
\end{abstract}

Keywords: Governance, Information Systems, COBIT Framework

\section{PENDAHULUAN}

Tata kelola teknologi informasi berkembang mulai dari sektor swasta, sektor publik, maupun organisasiorganisasi pemerintahan sebagai sarana untuk perbaikan kualitas pelayanan bagi masyarakat. Peranan tata kelola teknologi informasi tidak diragukan lagi dalam pencapaian tujuan suatu organisasi, seperti fungsi-fungsi manajemen. Intinya adalah bagaimana mengelola penggunaan TI agar menghasilkan output yang maksimal dalam organisasi, membantu proses pengambilan keputusan dan membantu proses pemecahan masalah. Prinsipprinsip tata kelola teknologi informasi harus dilakukan secara terintegrasi, sebagaimana fungsifungsi manajemen dilaksanakan pada sebuah organisasi publik (Swastika \& Putra, 2016).

Saat ini kegiatan tata kelola keamanan informasi belum dilakukan secara maksimal, banyak ditemukan kendala seperti sumber daya manusia yang kurang memahami aplikasi e-SKP sehingga berpotensi terjadinya error pada aplikasi, kemudian e-SKP masih menghadapi persoalan berkaitan dengan sering terjadi kehilangan data e-SKP dan belum ada solusi 
terkait masalah kehilangan data, maka diperlukan adanya audit tata kelola keamanan informasi. (Suryono, Darwis, \& Gunawan, 2018)

Pengelolaan informasi dalam bentuk web adalah salah satu bentuk implementasi teknologi informasi dalam hal pelayanan informasi publik. Melihat pentingnya informasi dalam proses bisnis PT. Maspion maka pengelolaan teknologi informasi pun perlu diperhatikan dan harus mampu untuk memperkecil resiko, dengan melakukan pengelolaan teknologi informasi dengan baik dan benar. Dalam makalah ini, penulis menggunakan Framework COBIT 4.1 untuk melakukan penilaian terhadap tingkat kematangan dari pengelolaan teknologi informasi PT.Maspion.

Salah satu metode pengelolaan teknologi informasi yang digunakan secara luas adalah tata kelola teknologi informasi yang terdapat pada COBIT (Control Objective for Information and Related Technology). COBIT dapat dikatakan sebagai kerangka kerja teknologi informasi yang dipublikasikan oleh ISACA (Information Systems Audit and Control Association).

dapat kami rumuskan permasalahan yang ada, antara lain: Bagaimana memanfaatkan framework COBIT 4.1 dalam meningkatkan tata kelola teknologi informasi PT. Maspion, sehingga dapat menghasilkan upaya peningkatan yang lebih baik lagi, Bagaimana melakukan evaluasi terhadap pemanfaatan teknologi serta melakukan penilaian maturity level dengan metode kuantitatif.

Tujuan penelitian ini adalah: Menganalisa pengelolaan TI yang sedang berjalan pada PT. Maspion, Melakukan kajian terhadap framework COBIT 4.1 dalam meningkatkan kematangan pemanfaatan teknologi informasi pada PT. Maspion, Memberikan rekomendasi dari hasil pengembangan framework COBIT pada PT. Maspion.

"Sistem informasi adalah suatu sistem didalam suatu organisasi yang mempertemukan kebutuhan pengelolaan transaksi harian, mendukung operasi, bersifat manajerial, dan kegiatan strategi dari suatu organisasi dan menyediakan pihak luar tertentu dengan laporan-laporan yang dibutuhkan" (Hutahaean, 2014)

"Sekumpulan komponen yang saling berhubungan, mengumpulkan atau mendapatkan, memproses, menyimpan dan mendistribusikan informasi untuk menunjang pengambilan keputusan dan pengawasan dalam suatu organisasi serta membantu manajer dalam mengambil keputusan" (Fauzan, 2015 : 237).

"Audit adalah suatu proses yang sistematis, mandiri, dan terdokumentasi untuk memperoleh bukti audit dan mengevaluasinya secara objektif untuk mennetukan sejauh makna kriteria audit terpenuhi" (Zakwan, Ratnawati, \& Hidayah, 2014).

Audit adalah suatu proses yang sistematis untuk memperoleh dan menilai bukti-bukti secara objektif, yang berkaitan dengan tindakan-tindakan dan kejadian-kejadian ekonomi untuk menentukan tingkat kesesuaian dengan kriteria yang telah diterapkan dan mengkomunikasikan hasilnya kepada pihak-pihak yang berkepentingan ( Fauzan \& Latifah, 2015 ).

Adapun kalimat-kalimat kunci dalam definisi audit sebagai berikut :

a. Proses yang sistematis

Yaitu mengandung makna sebagai rangkaian langkah atau prosedur yang logis, terencana, dan terorganisasi.

b. Memperoleh dan Menilai Bukti Secara Obyektif

Yaitu mengandung arti bahwa auditor memeriksa dasar-dasar yang diapaki untuk membuat aserasi atau pernyataan oleh manajemen dan melakukan penilaian tanpa sikap memihak.

c. Tindakan - Tindakan dan kejadian - kejadian ekonomi

Yaitu pernyataan tentang kejadian ekonomi yang merupakan informasi hasil proses akuntansi yang dibuat oleh individu atau suatu organisasi. Hal penting yang perlu dicatat adalah bahwa asersi-asersi tersebut dibuat oleh penyusun laporan keuangan, yaitu manajemen perusahaan atau pemerintah, untuk selanjutnya dikomunikasikan kepada para pengguna laporan keuangan, jadi bukan merupakan asersi dari auditor.

d. Mengkomunikasikan Hasilnya kepada Pihak-pihak yang Berkepentingan

Yaitu kegiatan terakhir dari suatu auditing atau pengauditan adalah menyampaikan temuan-temuan dan hasilnya kepada pengambil keputusan. Hasil dari auditing disebut pernyataan pendapat (opini) mengenai kesesuaiannya antara asersi atau pernyataan tersebut dengan kriteria yang ditetapkan.

e. Tingkat Kesesuaian Kriteria yang Telah Ditetapkan Yaitu secara spesifik memberikan alasan mengapa auditor tertarik pada pernyataan bukti-bukti pendukungnya. Namun agar komunikasi tersebut efisien dan dapat dimengerti dengan bahasa yang sama oleh para pengguna, maka diperlukan suatu kriteria yang disetujui bersama.

COBIT (Control Objectives for Information and Related Technology) adalah sebuah framework dan supporting toolset yang membantu manajer menjembatani jarak antara tujuan untuk keperluan pengendalian, permasalahan teknik (technical issue) dan resiko bisnis serta mengkomunikasikan level pengendalian kepada stakeholders ( Andry, 2016 ). COBIT membantu menyokong pengembangan kebijakan yang jelas dan langkah-langkah praktis terbaik yang dapat diambil untuk pengendalian teknologi informasi di seluruh perusahaan. COBIT dirancang antara lain untuk mendukung :

a. Manajemen eksekutif dan dewan direksi.

b. Bisnis dan manajemen teknologi informasi.

c. Pengelolaan, assurance, pengendalian dan security professionals.

"Cobit 4.1 (Control Objective for information and related technology) merupakan suatu framework yang terdiri dari domain dan proses yang digunakan 
untuk mengatur aktivitas dan logical structure." (Andry, 2018: 259).

COBIT menyediakan langkah-langkah praktis terbaik yang dapat diambil dan lebih difokuskan pada pengendalian (control), yang selanjutnya dijelaskan dalam tahap dan framework proses. Manfaat dari langkah-langkah praktis terbaik yang dapat diambil tersebut antara lain :

a. Membantu mengoptimalkan investasi teknologi informasi yang mungkin dapat dilakukan.

b. Menjamin pengiriman service.

Pada kerangka kerja COBIT terdapat domain domain utama yaitu seperti dalam ( Azizah, 2017 ) Dalam kerangka kerja sebelumnya, domain diidentifikasikan dengan memakai susunan manajemen yang akan digunakan dalam kegiatan harian organisasi. Kemudian empat domain yang lebih luas diidentifikasikan menjadi 4 domain utama, yaitu :

\section{1) Planning and Organization (PO)}

Domain Planning and Organization (PO) mencakup strategi dan taktik, dan perhatian atas identifikasi bagaimana TI secara maksimal dapat berkontribusi dalam pencapaian tujuan bisnis. Selain itu, realisasi dari visi strategis perlu direncanakan, dikomunikasikan, dan dikelola untuk berbagai perspektif yang berbeda. Terakhir, sebuah pengorganisasian yang baik serta infrastruktur teknologi harus di tempatkan di tempat yang semestinya.

\section{2) Acquisition and Implementation (AI)}

Untuk merealisasikan strategi TI, solusi TI perlu diidentifikasi, dikembangkan atau diperoleh, serta diimplementasikan, dan terintegrasi ke dalam proses bisnis. Selain itu, perubahan serta pemeliharaan sistem yang ada harus di cakup dalam domain ini untuk memastikan bahwa siklus hidup akan terus berlangsung untuk sistem ini.

Domain Domain Acquire and Implement (AI) berkaitan dengan implementasi solusi teknologi informasi dan integrasinya dalam proses bisnis organisasi untuk mewujudkan strategi teknologi informasi, juga meliputi perubahan dan maintenance yang dibutuhkan sistem yang sedang berjalan untuk memastikan daur hidup sistem tersebut tetap terjaga. Domain AI ini terdiri dari tujuh macam proses yang menyangkut mengenai mengidentifikasi solusi bagi perusahaan dan mengembangkan infrastruktur teknologi informasi.

AI 1 Mengidentifikasikan solusi otomatis

AI 2 Memperoleh dan memelihara perangkat lunak aplikasi

AI 3 Memperoleh dan memelihara infrastruktur teknologi

AI 4 Memungkinkan operasional dan penggunaan

AI 5 Memenuhi sumber daya teknologi informasi

AI 6 Mengelola perubahan

AI 7 Instalasi dan akreditasi solusi beserta perubahannya

\section{3) Delivery and Support (DS)}

Domain Delivery and Support (DS) memberikan fokus utama pada aspek penyampaian/pengiriman dari TI. Domain ini mencakup area-area seperti pengoperasian aplikasi-aplikasi dalam sistem TI dan hasilnya, dan juga, proses dukungan yang memungkinkan pengoperasian sistem TI tersebut dengan efektif dan efisien. Proses dukungan ini termasuk isu/masalah keamanan dan juga pelatihan.

4) Monitoring and Evaluation (ME)

Semua proses IT perlu dinilai secara teratur sepanjang waktu untuk menjaga kualitas dan pemenuhan atas syarat pengendalian. Domain ini menunjuk pada perlunya pengawasan manajemen atas proses pengendalian dalam organisasi serta penilaian independen yang dilakukan baik auditor internal maupun eksternal atau diperoleh dari sumber-sumber alternatif lainnya.

Microsoft Excel atau Microsoft Office Excel merupakan sebuah program aplikasi lembar kerja spreadsheet yang dibuat dan didistribusikan oleh Microsoft Corporation yang dapat dijalankan pada Microsoft Windows dan Mac.OS(Sarwandi, 2017:1). Aplikasi ini memiliki fitur kalkulasi dan pembuatan grafik dengan menggunakan strategi marketing Microsoft yang agresif, menjadikan Microsoft Excel sebagai salah satu program aplikasi komputer yang populer yang digunakan di dalam komputer mikro hingga sampai saat ini.

\section{METODOLOGI PENELITIAN}

Penelitian ini dilakukan dengan melakukan studi literature, kuisioner dan observasi terhadap perusahaan yang menjadi objek studi kasus. Adapun tahapan penelitian yang dilakukan adalah sebagai berikut:

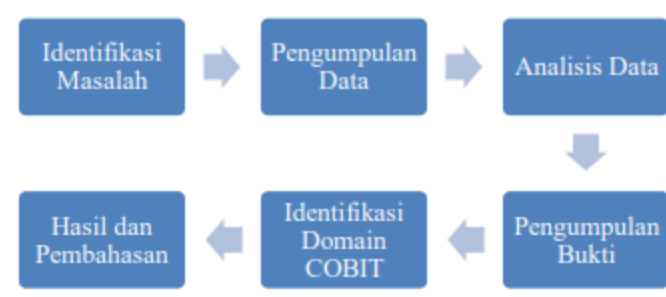

Sumber: (Suryono, Darwis, \& Gunawan, 2018) Gambar 1 Tahapan Penelitian

1. Langkah 1: Identifikasi Masalah

Pada tahap ini dilakukan COBIT 4.1 maping, peneliti menganalisa tujuan bisnis PT. Maspion yang telah ditetapkan dalam sistem informasi perusahaan untuk kemudian disesuaikan dengan COBIT 4.1

2. Langkah 2: Pengumpulan Data

Penelitian ini dilakukan melalui studi kasus di mana lokasi penelitian ini di PT Maspion. Studi ini mengukur kematangan mengendalikan proses teknologi informasi yang terjadi di lembaga-lembaga 
dalam rangka mencapai tujuan institusional didasarkan pada COBIT framework versi 4.1. Penelitian ini merupakan penelitian deskriptif, penelitian ini terdiri dari data primer dan sekunder. Data primer diperoleh dari wawancara dan sistem operator yang didasarkan pada instrumen penelitian dengan menggunakan kuisioner, survei dan observasi pada implementasikan teknologi informasi.

3. Langkah 3 : Analisis Data

Setelah dilakukan pengumpulan data, penulis melakukan analisis data. Analisis data yang dilakukan terdiri dari analsisi tingkat kematangan dan analsisi kesenjangan. Pengolahan dan dana analsisi hasil penelitian dilakukan dengan sistem komputerisasi Microsoft Excel.

4. Langkah 4 : Pengumpulan Bukti

Pada tahap ini, penulis melakukan pengumpulan bukti untuk menunjukkan adanya kekurangan.

5. Langkah 5: Identifikasi hasil COBIT

Pada tahap ini, penulis melakukan pengumpulan bukti untuk menunjukkan adanya kekurangan.

6. Langkah 5: Hasil dan Pembahasan

Pada tahap terakhir dibahas dan diolah data termasuk kedalam pengecekan pada maturity level sehingga akan ditemukan hasil dari penelitian.

\section{HASIL DAN PEMBAHASAN}

Responden dalam contoh kasus diambil dari bagian Akuntansi PT. Maspion.

\section{Master Data}

Tabel 1. AI 1

\begin{tabular}{|c|c|c|c|c|c|c|c|c|c|}
\hline \multirow{2}{*}{$\begin{array}{l}\text { Do } \\
\text { mai } \\
n\end{array}$} & \multirow{2}{*}{$\begin{array}{l}\text { Le } \\
\text { ve } \\
1\end{array}$} & \multirow{2}{*}{$\begin{array}{l}\text { Pern } \\
\text { yataa } \\
\mathrm{n}\end{array}$} & \multicolumn{5}{|c|}{ jawaban } & \multicolumn{2}{|c|}{$\begin{array}{c}\text { Total } \\
\text { Jawaban }\end{array}$} \\
\hline & & & R1 & $\mathrm{R} 2$ & R3 & R4 & R5 & $\begin{array}{l}\mathrm{Y} \\
\mathrm{a}\end{array}$ & $\begin{array}{l}\text { tid } \\
\text { ak }\end{array}$ \\
\hline \multirow{9}{*}{ AI1 } & \multirow{2}{*}{0} & P1 & $\mathrm{Ya}$ & $\begin{array}{c}\mathrm{Ti} \\
\mathrm{da} \\
\mathrm{k}\end{array}$ & $\mathrm{Ya}$ & $\begin{array}{c}\mathrm{Ti} \\
\mathrm{da} \\
\mathrm{k}\end{array}$ & $\begin{array}{c}\mathrm{Ti} \\
\mathrm{da} \\
\mathrm{k}\end{array}$ & 2 & 3 \\
\hline & & P2 & $\mathrm{Ya}$ & $\begin{array}{c}\mathrm{Ti} \\
\mathrm{da} \\
\mathrm{k}\end{array}$ & Ya & Ya & $\begin{array}{c}\mathrm{Ti} \\
\mathrm{da} \\
\mathrm{k}\end{array}$ & 4 & 1 \\
\hline & 1 & P3 & $\begin{array}{c}\mathrm{Ti} \\
\mathrm{da} \\
\mathrm{k}\end{array}$ & $\begin{array}{c}\mathrm{Ti} \\
\mathrm{da} \\
\mathrm{k}\end{array}$ & $\mathrm{Ya}$ & Ya & $\mathrm{Ya}$ & 4 & 1 \\
\hline & \multirow{2}{*}{2} & P4 & $\mathrm{Ya}$ & $\begin{array}{c}\mathrm{Ti} \\
\mathrm{da} \\
\mathrm{k}\end{array}$ & $\mathrm{Ya}$ & Ya & $\begin{array}{c}\mathrm{Ti} \\
\mathrm{da} \\
\mathrm{k}\end{array}$ & 3 & 2 \\
\hline & & P5 & $\mathrm{Ya}$ & $\begin{array}{c}\mathrm{Ti} \\
\mathrm{da} \\
\mathrm{k}\end{array}$ & $\mathrm{Ya}$ & $\begin{array}{c}\mathrm{Ti} \\
\mathrm{da} \\
\mathrm{k}\end{array}$ & $\mathrm{Ya}$ & 4 & 1 \\
\hline & \multirow{2}{*}{3} & P6 & $\mathrm{Ya}$ & $\begin{array}{c}\mathrm{Ti} \\
\mathrm{da} \\
\mathrm{k}\end{array}$ & $\mathrm{Ya}$ & $\mathrm{Ya}$ & $\mathrm{Ya}$ & 5 & 0 \\
\hline & & P7 & $\begin{array}{c}\mathrm{Ti} \\
\mathrm{da} \\
\mathrm{k}\end{array}$ & $\begin{array}{c}\mathrm{Ti} \\
\mathrm{da} \\
\mathrm{k}\end{array}$ & $\begin{array}{c}\mathrm{Ti} \\
\mathrm{da} \\
\mathrm{k}\end{array}$ & $\mathrm{Ya}$ & $\mathrm{Ya}$ & 3 & 2 \\
\hline & 4 & P8 & $\mathrm{Ya}$ & $\begin{array}{c}\mathrm{Ti} \\
\mathrm{da} \\
\mathrm{k}\end{array}$ & $\mathrm{Ya}$ & $\mathrm{Ya}$ & $\mathrm{Ya}$ & 5 & 0 \\
\hline & 5 & P9 & $\mathrm{Ya}$ & $\mathrm{Ya}$ & $\mathrm{Ya}$ & $\mathrm{Ya}$ & $\begin{array}{c}\mathrm{Ti} \\
\mathrm{da} \\
\mathrm{k}\end{array}$ & 4 & 1 \\
\hline
\end{tabular}

Sumber: (Saryoko et al., 2021)
Tabel 2. AI 2

\begin{tabular}{|c|c|c|c|c|c|c|c|c|c|}
\hline \multirow{2}{*}{$\begin{array}{l}\text { Do } \\
\text { mai } \\
n\end{array}$} & \multirow{2}{*}{$\begin{array}{l}\text { Le } \\
\text { ve } \\
1\end{array}$} & \multirow{2}{*}{$\begin{array}{l}\text { Pern } \\
\text { yataa } \\
\mathrm{n}\end{array}$} & \multicolumn{5}{|c|}{ jawaban } & \multicolumn{2}{|c|}{$\begin{array}{c}\text { Total } \\
\text { Jawaban }\end{array}$} \\
\hline & & & R1 & R2 & R3 & R4 & R5 & $\begin{array}{l}\mathrm{Y} \\
\mathrm{a}\end{array}$ & $\begin{array}{l}\text { tid } \\
\text { ak }\end{array}$ \\
\hline \multirow{8}{*}{ AI2 } & \multirow{2}{*}{0} & P1 & $\mathrm{Ya}$ & $\begin{array}{c}\mathrm{Ti} \\
\mathrm{da} \\
\mathrm{k}\end{array}$ & $\mathrm{Ya}$ & $\begin{array}{c}\mathrm{Ti} \\
\mathrm{da} \\
\mathrm{k}\end{array}$ & $\begin{array}{c}\mathrm{Ti} \\
\mathrm{da} \\
\mathrm{k}\end{array}$ & 2 & 3 \\
\hline & & $\mathrm{P}$ & $\mathrm{Ya}$ & $\mathrm{Ya}$ & $\mathrm{Ya}$ & $\mathrm{Ya}$ & $\begin{array}{c}\mathrm{Ti} \\
\mathrm{da} \\
\mathrm{k}\end{array}$ & 4 & 1 \\
\hline & 1 & P3 & $\begin{array}{c}\mathrm{Ti} \\
\mathrm{da} \\
\mathrm{k}\end{array}$ & $\mathrm{Ya}$ & $\mathrm{Ya}$ & $\mathrm{Ya}$ & $\mathrm{Ya}$ & 4 & 1 \\
\hline & \multirow{2}{*}{2} & P4 & $\mathrm{Ya}$ & $\begin{array}{c}\mathrm{Ti} \\
\mathrm{da} \\
\mathrm{k}\end{array}$ & $\mathrm{Ya}$ & $\mathrm{Ya}$ & $\begin{array}{c}\mathrm{Ti} \\
\mathrm{da} \\
\mathrm{k}\end{array}$ & 3 & 2 \\
\hline & & P5 & $\mathrm{Ya}$ & $\mathrm{Ya}$ & $\mathrm{Ya}$ & $\begin{array}{c}\mathrm{Ti} \\
\mathrm{da} \\
\mathrm{k}\end{array}$ & $\mathrm{Ya}$ & 4 & 1 \\
\hline & 3 & P6 & Ya & $\mathrm{Ya}$ & $\mathrm{Ya}$ & $\mathrm{Ya}$ & $\mathrm{Ya}$ & 5 & 0 \\
\hline & 4 & P7 & $\begin{array}{c}\mathrm{Ti} \\
\mathrm{da} \\
\mathrm{k}\end{array}$ & $\mathrm{Ya}$ & $\begin{array}{c}\mathrm{Ti} \\
\mathrm{da} \\
\mathrm{k}\end{array}$ & $\mathrm{Ya}$ & $\mathrm{Ya}$ & 3 & 2 \\
\hline & 5 & P8 & $\mathrm{Ya}$ & $\mathrm{Ya}$ & $\mathrm{Ya}$ & $\mathrm{Ya}$ & $\mathrm{Ya}$ & 5 & 0 \\
\hline
\end{tabular}

Sumber: (Saryoko et al., 2021)

Tabel 3. AI 3

\begin{tabular}{|c|c|c|c|c|c|c|c|c|c|}
\hline \multirow{2}{*}{$\begin{array}{l}\text { Do } \\
\text { mai } \\
n\end{array}$} & \multirow{2}{*}{$\begin{array}{l}\text { Le } \\
\text { ve } \\
1\end{array}$} & \multirow{2}{*}{$\begin{array}{l}\text { Pern } \\
\text { yataa } \\
n\end{array}$} & \multicolumn{5}{|c|}{ jawaban } & \multicolumn{2}{|c|}{$\begin{array}{c}\text { Total } \\
\text { Jawaban }\end{array}$} \\
\hline & & & $\mathrm{R} 1$ & $\mathrm{R} 2$ & $\begin{array}{l}\mathrm{R} \\
3\end{array}$ & $\mathrm{R} 4$ & R5 & $\begin{array}{l}\mathrm{Y} \\
\mathrm{a}\end{array}$ & $\begin{array}{l}\text { tid } \\
\text { ak }\end{array}$ \\
\hline \multirow{6}{*}{ AI3 } & 0 & P1 & $\mathrm{Ya}$ & $\begin{array}{c}\mathrm{Ti} \\
\mathrm{da} \\
\mathrm{k}\end{array}$ & $\begin{array}{l}\mathrm{Y} \\
\mathrm{a}\end{array}$ & $\begin{array}{c}\mathrm{Ti} \\
\mathrm{da} \\
\mathrm{k}\end{array}$ & $\begin{array}{c}\mathrm{Ti} \\
\mathrm{da} \\
\mathrm{k}\end{array}$ & 2 & 3 \\
\hline & 1 & $\mathrm{P} 2$ & $\mathrm{Ya}$ & $\mathrm{Ya}$ & $\begin{array}{l}\mathrm{Y} \\
\mathrm{a}\end{array}$ & $\mathrm{Ya}$ & $\begin{array}{c}\mathrm{Ti} \\
\mathrm{da} \\
\mathrm{k}\end{array}$ & 4 & 1 \\
\hline & 2 & P3 & $\begin{array}{c}\mathrm{Ti} \\
\mathrm{da} \\
\mathrm{k}\end{array}$ & $\mathrm{Ya}$ & $\begin{array}{l}\mathrm{Y} \\
\mathrm{a}\end{array}$ & $\mathrm{Ya}$ & $\mathrm{Ya}$ & 4 & 1 \\
\hline & 3 & $\mathrm{P} 4$ & $\mathrm{Ya}$ & $\begin{array}{c}\mathrm{Ti} \\
\mathrm{da} \\
\mathrm{k} \\
\end{array}$ & $\begin{array}{l}Y \\
\mathrm{a}\end{array}$ & $\mathrm{Ya}$ & $\begin{array}{c}\mathrm{Ti} \\
\mathrm{da} \\
\mathrm{k}\end{array}$ & 3 & 2 \\
\hline & 4 & P5 & $\mathrm{Ya}$ & $\mathrm{Ya}$ & $\begin{array}{l}\mathrm{Y} \\
\mathrm{a}\end{array}$ & $\begin{array}{c}\mathrm{Ti} \\
\mathrm{da} \\
\mathrm{k}\end{array}$ & $\mathrm{Ya}$ & 4 & 1 \\
\hline & 5 & P6 & $\mathrm{Ya}$ & $\mathrm{Ya}$ & $\begin{array}{l}\mathrm{Y} \\
\mathrm{a}\end{array}$ & $\mathrm{Ya}$ & $\mathrm{Ya}$ & 5 & 0 \\
\hline
\end{tabular}

Sumber: (Saryoko et al., 2021)

Tabel 4. AI 4

\begin{tabular}{|c|c|c|c|c|c|c|c|c|c|}
\hline \multirow{2}{*}{$\begin{array}{l}\text { Do } \\
\text { mai } \\
n\end{array}$} & \multirow{2}{*}{$\begin{array}{l}\text { Le } \\
\text { ve } \\
1\end{array}$} & \multirow{2}{*}{$\begin{array}{l}\text { Pern } \\
\text { yataa } \\
n\end{array}$} & \multicolumn{5}{|c|}{ jawaban } & \multicolumn{2}{|c|}{$\begin{array}{c}\text { Total } \\
\text { Jawaban }\end{array}$} \\
\hline & & & R1 & R2 & $\begin{array}{l}\mathrm{R} \\
3\end{array}$ & $\mathrm{R} 4$ & R5 & $\begin{array}{l}\mathrm{Y} \\
\mathrm{a}\end{array}$ & $\begin{array}{l}\text { tid } \\
\text { ak }\end{array}$ \\
\hline \multirow{4}{*}{ AI4 } & 0 & P1 & $\mathrm{Ya}$ & $\begin{array}{c}\mathrm{Ti} \\
\mathrm{da} \\
\mathrm{k} \\
\end{array}$ & $\begin{array}{l}\mathrm{Y} \\
\mathrm{a}\end{array}$ & $\begin{array}{c}\mathrm{Ti} \\
\mathrm{da} \\
\mathrm{k} \\
\end{array}$ & $\begin{array}{l}\mathrm{Ti} \\
\mathrm{da} \\
\mathrm{k}\end{array}$ & 2 & 3 \\
\hline & 1 & P2 & $\mathrm{Ya}$ & Ya & $\begin{array}{l}\mathrm{Y} \\
\mathrm{a}\end{array}$ & Ya & $\begin{array}{c}\mathrm{Ti} \\
\mathrm{da} \\
\mathrm{k}\end{array}$ & 4 & 1 \\
\hline & 2 & P3 & $\begin{array}{c}\mathrm{Ti} \\
\mathrm{da} \\
\mathrm{k}\end{array}$ & Ya & $\begin{array}{l}\mathrm{Y} \\
\mathrm{a}\end{array}$ & Ya & Ya & 4 & 1 \\
\hline & 3 & P4 & $\mathrm{Ya}$ & $\begin{array}{c}\mathrm{Ti} \\
\mathrm{da} \\
\mathrm{k}\end{array}$ & $\begin{array}{l}\mathrm{Y} \\
\mathrm{a}\end{array}$ & Ya & $\begin{array}{c}\mathrm{Ti} \\
\mathrm{da} \\
\mathrm{k}\end{array}$ & 3 & 2 \\
\hline
\end{tabular}

Sumber: (Saryoko et al., 2021) 
Tabel 5. AI 5

\begin{tabular}{|c|c|c|c|c|c|c|c|c|c|}
\hline \multirow{2}{*}{$\begin{array}{l}\text { Do } \\
\text { mai } \\
n\end{array}$} & \multirow{2}{*}{$\begin{array}{l}\text { Le } \\
\text { ve } \\
1\end{array}$} & \multirow{2}{*}{$\begin{array}{l}\text { Pern } \\
\text { yataa } \\
n\end{array}$} & \multicolumn{5}{|c|}{ jawaban } & \multicolumn{2}{|c|}{$\begin{array}{c}\text { Total } \\
\text { Jawaban }\end{array}$} \\
\hline & & & R1 & R2 & $\begin{array}{l}\mathrm{R} \\
3 \\
\end{array}$ & R4 & R5 & $\begin{array}{l}\mathrm{Y} \\
\mathrm{a}\end{array}$ & $\begin{array}{l}\text { tid } \\
\text { ak }\end{array}$ \\
\hline \multirow{6}{*}{ AI5 } & 0 & $\mathrm{P} 1$ & $\mathrm{Ya}$ & $\begin{array}{c}\mathrm{Ti} \\
\mathrm{da} \\
\mathrm{k}\end{array}$ & $\begin{array}{l}\mathrm{Y} \\
\mathrm{a}\end{array}$ & $\begin{array}{l}\mathrm{Ti} \\
\mathrm{da} \\
\mathrm{k}\end{array}$ & $\begin{array}{c}\mathrm{Ti} \\
\mathrm{da} \\
\mathrm{k}\end{array}$ & 2 & 3 \\
\hline & 1 & $\mathrm{P} 2$ & $\mathrm{Ya}$ & $\mathrm{Ya}$ & $\begin{array}{l}\mathrm{Y} \\
\mathrm{a}\end{array}$ & $\mathrm{Ya}$ & $\begin{array}{c}\mathrm{Ti} \\
\mathrm{da} \\
\mathrm{k}\end{array}$ & 4 & 1 \\
\hline & 2 & P3 & $\begin{array}{c}\mathrm{Ti} \\
\mathrm{da} \\
\mathrm{k}\end{array}$ & $\mathrm{Ya}$ & $\begin{array}{l}\mathrm{Y} \\
\mathrm{a}\end{array}$ & $\mathrm{Ya}$ & $\mathrm{Ya}$ & 4 & 1 \\
\hline & 3 & $\mathrm{P} 4$ & $\mathrm{Ya}$ & $\begin{array}{c}\mathrm{Ti} \\
\mathrm{da} \\
\mathrm{k}\end{array}$ & $\begin{array}{l}\mathrm{Y} \\
\mathrm{a}\end{array}$ & $\mathrm{Ya}$ & $\begin{array}{c}\mathrm{Ti} \\
\mathrm{da} \\
\mathrm{k}\end{array}$ & 3 & 2 \\
\hline & 4 & P5 & $\mathrm{Ya}$ & $\mathrm{Ya}$ & $\begin{array}{l}\mathrm{Y} \\
\mathrm{a}\end{array}$ & $\begin{array}{c}\mathrm{Ti} \\
\mathrm{da} \\
\mathrm{k}\end{array}$ & $\mathrm{Ya}$ & 4 & 1 \\
\hline & 5 & P6 & $\mathrm{Ya}$ & $\mathrm{Ya}$ & $\begin{array}{l}\mathrm{Y} \\
\mathrm{a}\end{array}$ & $\mathrm{Ya}$ & $\mathrm{Ya}$ & 5 & 0 \\
\hline
\end{tabular}

Sumber: (Saryoko et al., 2021)

Tabel 6. AI 6

\begin{tabular}{|c|c|c|c|c|c|c|c|c|c|}
\hline \multirow{2}{*}{$\begin{array}{c}\text { Do } \\
\text { mai } \\
n\end{array}$} & \multirow{2}{*}{$\begin{array}{c}\text { Le } \\
\text { ve } \\
1\end{array}$} & \multirow{2}{*}{$\begin{array}{c}\text { Pern } \\
\text { yataa } \\
n\end{array}$} & \multicolumn{5}{|c|}{ jawaban } & \multicolumn{2}{|c|}{$\begin{array}{c}\text { Total } \\
\text { Jawaban }\end{array}$} \\
\hline & & & R1 & R2 & R3 & R4 & R5 & $\begin{array}{l}\mathrm{Y} \\
\mathrm{a}\end{array}$ & $\begin{array}{l}\text { tid } \\
\text { ak }\end{array}$ \\
\hline \multirow{7}{*}{ AI6 } & 0 & P1 & Ya & $\begin{array}{c}\mathrm{Ti} \\
\mathrm{da} \\
\mathrm{k}\end{array}$ & Ya & $\begin{array}{c}\mathrm{Ti} \\
\mathrm{da} \\
\mathrm{k}\end{array}$ & $\begin{array}{c}\mathrm{Ti} \\
\mathrm{da} \\
\mathrm{k}\end{array}$ & 2 & 3 \\
\hline & 1 & P2 & $\mathrm{Ya}$ & $\mathrm{Ya}$ & $\mathrm{Ya}$ & $\mathrm{Ya}$ & $\begin{array}{c}\mathrm{Ti} \\
\mathrm{da} \\
\mathrm{k} \\
\end{array}$ & 4 & 1 \\
\hline & 2 & P3 & $\begin{array}{c}\mathrm{Ti} \\
\mathrm{da} \\
\mathrm{k}\end{array}$ & $\mathrm{Ya}$ & Ya & Ya & $\mathrm{Ya}$ & 4 & 1 \\
\hline & 3 & P4 & Ya & $\begin{array}{c}\mathrm{Ti} \\
\mathrm{da} \\
\mathrm{k}\end{array}$ & Ya & Ya & $\begin{array}{c}\mathrm{Ti} \\
\mathrm{da} \\
\mathrm{k}\end{array}$ & 3 & 2 \\
\hline & 4 & P5 & Ya & $\mathrm{Ya}$ & $\mathrm{Ya}$ & $\begin{array}{c}\mathrm{Ti} \\
\mathrm{da} \\
\mathrm{k}\end{array}$ & $\mathrm{Ya}$ & 4 & 1 \\
\hline & \multirow[b]{2}{*}{5} & P6 & Ya & $\mathrm{Ya}$ & Ya & Ya & Ya & 5 & 0 \\
\hline & & P7 & Ya & $\begin{array}{c}\mathrm{Ti} \\
\mathrm{da} \\
\mathrm{k}\end{array}$ & $\begin{array}{c}\mathrm{Ti} \\
\mathrm{da} \\
\mathrm{k}\end{array}$ & Ya & $\begin{array}{c}\mathrm{Ti} \\
\mathrm{da} \\
\mathrm{k}\end{array}$ & 2 & 3 \\
\hline
\end{tabular}

Sumber: (Saryoko et al., 2021)

Tabel 7. AI 7

\begin{tabular}{|c|c|c|c|c|c|c|c|c|c|}
\hline \multirow{2}{*}{$\begin{array}{l}\text { Do } \\
\text { mai } \\
n\end{array}$} & \multirow{2}{*}{$\begin{array}{l}\text { Le } \\
\text { ve } \\
1\end{array}$} & \multirow{2}{*}{$\begin{array}{l}\text { Pern } \\
\text { yataa } \\
\mathrm{n}\end{array}$} & \multicolumn{5}{|c|}{ jawaban } & \multicolumn{2}{|c|}{$\begin{array}{c}\text { Total } \\
\text { Jawaban }\end{array}$} \\
\hline & & & R1 & $\mathrm{R} 2$ & R3 & R4 & R5 & $\begin{array}{l}\mathrm{Y} \\
\mathrm{a}\end{array}$ & $\begin{array}{l}\text { tid } \\
\text { ak }\end{array}$ \\
\hline \multirow{6}{*}{ AI7 } & \multirow{2}{*}{0} & P1 & Ya & $\begin{array}{c}\mathrm{Ti} \\
\mathrm{da} \\
\mathrm{k}\end{array}$ & $\mathrm{Ya}$ & $\begin{array}{c}\mathrm{Ti} \\
\mathrm{da} \\
\mathrm{k}\end{array}$ & $\begin{array}{c}\mathrm{Ti} \\
\mathrm{da} \\
\mathrm{k}\end{array}$ & 2 & 3 \\
\hline & & P2 & Ya & $\mathrm{Ya}$ & $\mathrm{Ya}$ & $\mathrm{Ya}$ & $\begin{array}{c}\mathrm{Ti} \\
\mathrm{da} \\
\mathrm{k}\end{array}$ & 4 & 1 \\
\hline & \multirow{3}{*}{1} & P3 & $\begin{array}{c}\mathrm{Ti} \\
\mathrm{da} \\
\mathrm{k}\end{array}$ & $\mathrm{Ya}$ & $\mathrm{Ya}$ & $\mathrm{Ya}$ & $\mathrm{Ya}$ & 4 & 1 \\
\hline & & P4 & $\mathrm{Ya}$ & $\begin{array}{c}\mathrm{Ti} \\
\mathrm{da} \\
\mathrm{k}\end{array}$ & $\mathrm{Ya}$ & $\mathrm{Ya}$ & $\begin{array}{c}\mathrm{Ti} \\
\mathrm{da} \\
\mathrm{k}\end{array}$ & 3 & 2 \\
\hline & & P5 & Ya & $\mathrm{Ya}$ & $\mathrm{Ya}$ & $\begin{array}{c}\mathrm{Ti} \\
\mathrm{da} \\
\mathrm{k}\end{array}$ & $\mathrm{Ya}$ & 4 & 1 \\
\hline & 2 & P6 & $\mathrm{Ya}$ & $\mathrm{Ya}$ & $\mathrm{Ya}$ & $\mathrm{Ya}$ & $\mathrm{Ya}$ & 5 & 0 \\
\hline
\end{tabular}

\begin{tabular}{|c|c|c|c|c|c|c|c|c|}
\hline \multirow[t]{2}{*}{3} & P7 & $\begin{array}{c}\mathrm{Ti} \\
\mathrm{da} \\
\mathrm{k}\end{array}$ & Ya & $\begin{array}{c}\mathrm{Ti} \\
\mathrm{da} \\
\mathrm{k}\end{array}$ & $\mathrm{Ya}$ & $\mathrm{Ya}$ & 3 & 2 \\
\hline & P8 & $\mathrm{Ya}$ & $\mathrm{Ya}$ & $\mathrm{Ya}$ & $\mathrm{Ya}$ & $\mathrm{Ya}$ & 5 & 0 \\
\hline 4 & P9 & $\mathrm{Ya}$ & $\mathrm{Ya}$ & Ya & Ya & $\begin{array}{c}\mathrm{Ti} \\
\mathrm{da} \\
\mathrm{k}\end{array}$ & 4 & 1 \\
\hline \multirow{2}{*}{5} & P10 & $\mathrm{Ya}$ & $\begin{array}{c}\mathrm{Ti} \\
\mathrm{da} \\
\mathrm{k}\end{array}$ & Ya & $\begin{array}{c}\mathrm{Ti} \\
\mathrm{da} \\
\mathrm{k}\end{array}$ & $\mathrm{Ya}$ & 3 & 2 \\
\hline & P11 & $\begin{array}{c}\mathrm{Ti} \\
\mathrm{da} \\
\mathrm{k}\end{array}$ & Ya & Ya & $\begin{array}{c}\mathrm{Ti} \\
\mathrm{da} \\
\mathrm{k}\end{array}$ & $\begin{array}{c}\mathrm{Ti} \\
\mathrm{da} \\
\mathrm{k}\end{array}$ & 2 & 3 \\
\hline
\end{tabular}

Sumber: (Saryoko et al., 2021)

Analisa dilakukan untuk mengetahui tingkat kematangan Akuntansi di PT. Maspion terhadap control objective. Control objective yang akan dilakukan penilaian adalah control objective yang berada pada domain AI (Acquire and Impement).

Berikut ini adalah hasil kuisioner untuk domain AI yang dapat diperlihatkan dalam tabel sebagai berikut:

Tabel 8. Hasil Kuesioner

\begin{tabular}{|l|c|c|c|}
\hline \multicolumn{1}{|c|}{ Control Objective } & $\begin{array}{c}\text { Jumlah } \\
\text { Pertanyaan }\end{array}$ & Index & $\begin{array}{c}\text { Maturity } \\
\text { Level }\end{array}$ \\
\hline $\begin{array}{l}\text { AI 1 Mengidentifikasi } \\
\text { Otomasi Solusi }\end{array}$ & 9 & 3,23 & 3 \\
\hline $\begin{array}{l}\text { AI 2 Memperoleh dan } \\
\text { Memelihara Aplikasi } \\
\text { Perangkat Lunak }\end{array}$ & 8 & 2,68 & 3 \\
\hline $\begin{array}{l}\text { AI 3 Mendapatkan dan } \\
\text { Memelihara } \\
\text { Infrastruktur Teknologi }\end{array}$ & 6 & 2,88 & 3 \\
\hline $\begin{array}{l}\text { AI 4 Menjalankan dan } \\
\text { Menggunakan Operasi }\end{array}$ & 4 & 1,47 & 3 \\
\hline $\begin{array}{l}\text { AI 5 Mendapatkan } \\
\text { sumber daya IT }\end{array}$ & 6 & 2,57 & 3 \\
\hline $\begin{array}{l}\text { AI 6 Mengelola } \\
\text { Perubahan }\end{array}$ & 7 & 2,75 & 3 \\
\hline $\begin{array}{l}\text { AI 7 Memasang dan } \\
\text { Mengakreditasi Solusi } \\
\text { serta Perubahan }\end{array}$ & 11 & 2,48 & 3 \\
\hline
\end{tabular}

Sumber: (Saryoko et al., 2021)

Untuk mengetahui tingkat kematangan akutansi saat ini di gunakan kuisioner cobit maturity model. Kuisioner dibuat berdasarkan kriteria kematangan yang diterapkan pada cobit 4.0. untuk setiap proses yang terdapat dalam domain AI. Kuisioner menggunakan skala likert dengan bobot untuk setiap pertanyaan ditetapkan 0 dan 1 . Pertanyaan dengan jawabanya ya (Y) akan dikonversikan pada nilai 1, sebaliknya untuk jawaban tidak (T) akan dikonversikan pada nilai 0 .

Penilaian tingkat kematangan setiap control objective atau proses akutansi pada domain AI mengacu pada model maturity level cobit versi 4 dengan kriteria index penilaian sebagai berikut. 
Tabel.9

\begin{tabular}{|c|c|}
\hline $0-0.50$ & Non-Exsistent \\
\hline $0.51-1.50$ & Initial/ AD Hoc \\
\hline $1.51-2.50$ & $\begin{array}{c}\text { Repeatable But } \\
\text { Measurable }\end{array}$ \\
\hline $2.51-3.50$ & Defiened Process \\
\hline $3.51-4.50$ & Managed and Measurable \\
\hline $4.51-5.00$ & Optimased \\
\hline
\end{tabular}

Sumber: (Dazki, Islami, \& Atmojo, 2020)

Dengan melihat kondisi tingkat kematangan control objective domain AI yang berjalan pada PT. Maspion saat ini terhadap kondisi ideal tingkat kematangan control objective yang diinginkan, maka akan memunculkan suatu penyesuaian dengan kondisi normative berdasarkan COBIT versi 4.0.penyesuaian dilakukan untuk menutup Gap yang diciptakan dari tingkat kematangan proses saat ini (current maturity level) dengan kondisi ideal tingkat kematangan proses yang diinginkan (target maturity level), sebagai acuan dari rekomendasi yang penulis ambil adalah dengan melihat detail control objective.

Gambar grafik current maturity level dan target maturity level untuk domain AI dapat dilihat pada gambar berikut ini.

Tabel 11. Maturity Level

\begin{tabular}{|c|c|c|c|}
\hline Domain & Proses & $\begin{array}{l}\text { Curent } \\
\text { Maturity }\end{array}$ & $\begin{array}{l}\text { Expected } \\
\text { Maturity }\end{array}$ \\
\hline AI1 & $\begin{array}{l}\text { Mengidentifikasi } \\
\text { Otomasi Solusi }\end{array}$ & 3,23 & 3 \\
\hline AI2 & $\begin{array}{l}\text { Memperoleh dan } \\
\text { Memelihara Aplikasi } \\
\text { Perangkat Lunak }\end{array}$ & 2,68 & 3 \\
\hline $\mathrm{AI} 3$ & $\begin{array}{l}\text { Mendapatkan dan } \\
\text { Memelihara } \\
\text { Infrastruktur } \\
\text { Teknologi }\end{array}$ & 2,88 & 3 \\
\hline AI4 & $\begin{array}{l}\text { Menjalankan dan } \\
\text { Menggunakan } \\
\text { Operasi }\end{array}$ & 1,47 & 3 \\
\hline AI5 & $\begin{array}{l}\text { Mendapatkan } \\
\text { sumber daya IT }\end{array}$ & 2,57 & 3 \\
\hline AI6 & $\begin{array}{l}\text { Mengelola } \\
\text { Perubahan }\end{array}$ & 2,75 & 3 \\
\hline AI7 & $\begin{array}{ll}\text { Memasang dan } & \text { dengakreditasi } \\
\text { Solusi serta } \\
\text { Perubahan }\end{array}$ & 2,48 & 3 \\
\hline
\end{tabular}

Sumber: (Saryoko et al., 2021)

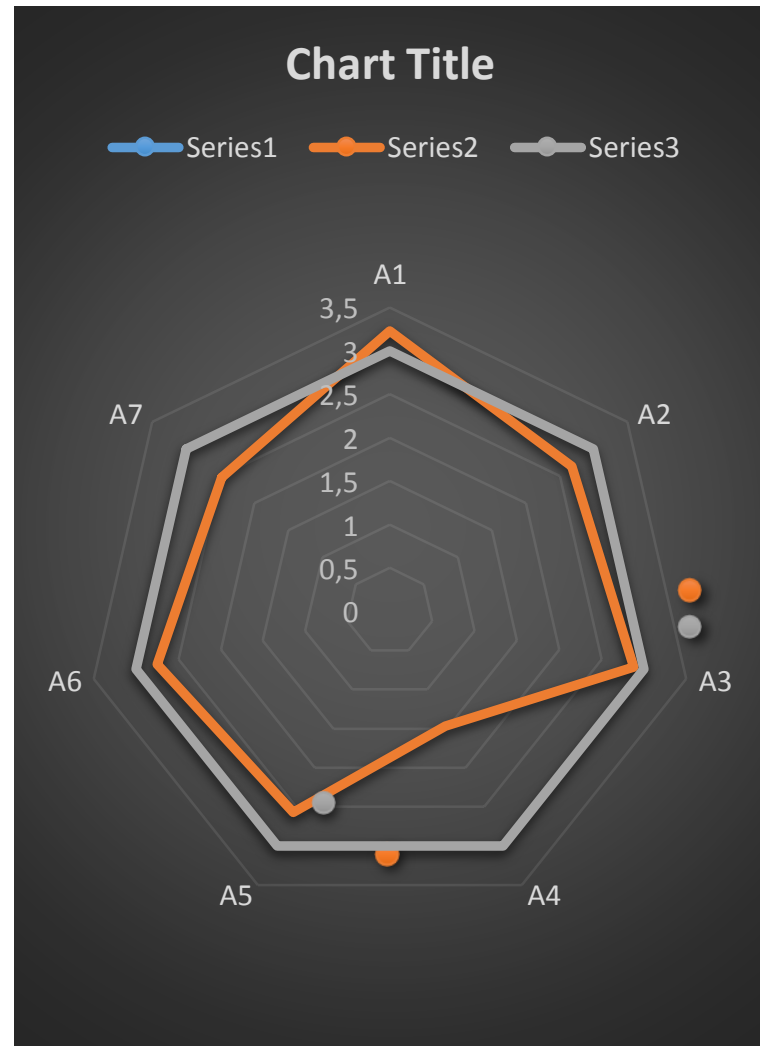

Sumber: (Saryoko et al., 2021)

Gambar 2. Radar Gap Maturity Level

\section{KESIMPULAN}

Berdasarkan dari hasil penelitian yang penulis lakukan, maka penulis dapat menyampaikan kesimpulannya adalah evalusai pelaksanaan tata kelola pada PT. Maspion saat ini berada pada level 3 untuk domain A1. Tingkat kematangan (maturity level) tata kelola yang dilakukan di PT. Maspion adalah Domain AI berada pada level 3 (Defiened Process) dimana proses sudah berkembang, prosedur yang sama dilakukan oleh yang berbeda, belum ada komunikasi atau pelatihan formal atas prosedur standard dan tanggung jawab diserahkan pada individu, terdapat kepercayaan yang tinggi pada kemampuan individu, sehingga kesalahan sangat mungkin terjadi.

\section{REFERENSI}

Andry, J. F. (2018). Audit Sistem Informasi Absensi Pada Pt. Bank Central Asia Tbk Menggunakan Cobit 4.1. Jurnal Teknik Informatika Dan Sistem Informasi, 3(2), 259-268. https://doi.org/10.28932/jutisi.v3i2.615

Fauzan. (2015). Audit Tata Kelola Teknologi Informasi Untuk Mengontrol Manajemen 
Kualitas Menggunakan Cobit 4.1 ( Studi Kasus : PT Nikkatsu Electric Works ). Jurnal Teknik Informatika Dan Sistem Informasi, 1(3), 235-244.

Hutahaean, J. (2014). Konsep Sistem Informasi (1st ed.). DEEPUBLISH.

Kasus, S., Xyz, U., \& Soepomo, P. (2013). Pembuatan Model Tata Kelola It Untuk Proses Akademik Menggunakan Cobit 4 . 1 (Studi Kasus: Universitas XYZ). Jurnal Sarjana Teknik Informatiika, 1(1), 287-296.

Megawati, \& Amrullah, F. (2014). Evaluasi Tingkat Kematangan Teknologi Informasi Dengan Menggunakan Model Maturity Level Cobit 4.1 (Studi Kasus Pt. Bri Cabang Bangkinang). Jurnal Sains Dan Teknologi Industri, 12(1), 99105. Retrieved from http://ejournal.uinsuska.ac.id/index.php/sitekin/article/view/779/ 728

Saryoko, A., Junaaedi, A., Dalis, S., \& Rivaldy, F. (2021). Tata Kelola Sistem Informasi PT. Maspion Menggunakan Framework Cobit 4.1 Domain Acquire And Implement.

Sihotang, H. T. (2015). Penerapan Tata Kelola Teknologi Informasi Dengan Menggunakan Cobit Framework 4.1 Studi Kasus pada PT. Perkebunan Nusantara III Medan (Persero). Jurnal Mantik Penusa, 17(1), 1-7. Retrieved from http://ejurnal.pelitanusantara.ac.id/index.php/mantik/a rticle/view/119/35
Swastika, I. P. A., \& Putra, I. G. L. A. R. (2016). Audit Sistem Informasi dan Tata Kelola Teknologi Informasi. Andi Offset.

Zakwan, S., Ratnawati, S., \& Hidayah, N. A. (2014). Audit Tata Kelola Sumber Daya Teknologi Informasi Dengan Kerangka Kerja Cobit 4.1 Untuk Evaluasi Manajemen Pada Badan Pengawasan Keuangan Dan Pembangunan. Studia Informatika: Jurnal Sistem Informasi, 7(2014), 1-16.

\section{PROFIL PENULIS}

Andi Saryoko, M.Kom. Lahir di kota Klaten, Jawa Tengah pada tanggal 04 Oktober 1981. Tamat program Diploma III (D3) tahun 2005 Program Studi Komputerisasi Akuntansi di AMIK BSI Jakarta, Tamat S1 tahun 2008 Program Studi Sistem Informasi di STMIK Nusa Mandiri Jakarta, Tamat S2 tahun 2011 Program Studi Ilmu Komputer (S2) Konsentrasi Management Information System (Ilmu Komputer) di Program Pasca Sarjana STMIK Nusamandiri Jakarta. Menjadi Dosen tetap di AMIK BSI Jakarta sejak tahun 2008, dan memiliki Jabatan Fungsional Dosen Asisten Ahli TMT 1 April 2014, dan Lektor TMT 1 Desember 2018. Menjadi Dosen Tetap Universitas Nusa Mandiri sejak tahun 2014. Sudah pernah melakukan penelitian dan artikelnya terbit di beberapa jurnal nasional terakreditasi, antara lain Jurnal Teknologi, Jurnal Cakrawala, dan Jurnal Pilar, Jurnal Paradigma, Jurnal Perspektif, Jurnal Sistem Informasi, Jurnal Informatika dll. 